\title{
TRIPLE NEGATIVE BREAST CANCER - CURRENT STATUS AND PROSPECTIVE TARGETED TREATMENT BASED ON HER1 (EGFR), TOP2A AND C-MYC GENE ASSESSMENT
}

\author{
Katerina Bouchalova ${ }^{\text {a\#}}$, Magdalena Cizkova ${ }^{\mathrm{a}, \mathrm{b}}$, Karel Cwiertka ${ }^{\mathrm{b}}$, Radek Trojanec ${ }^{\mathrm{a}}$, \\ Marian Hajduch**
}

\author{
a Laboratory of Experimental Medicine, Department of Paediatrics, Faculty of Medicine and Dentistry, Palacky University \\ and University Hospital, Puskinova 6, 77520 Olomouc, Czech Republic \\ ${ }^{b}$ Department of Oncology, Faculty of Medicine and Dentistry, Palacky University and University Hospital, I.P.Pavlova 6, \\ 77520 Olomouc, Czech Republic \\ \# Authors equally contributed to the work \\ e-mail:hajduchm@gmail.com
}

Received: March 3, 2009; Accepted: March 10, 2009

Key words: EGFR(HER1)/TOP2A/C-MYC/Targeted therapy/Biological therapy/Triple negative breast cancer

Background: Every year about one million women worldwide are diagnosed with breast cancer which is the most common malignancy in female. Of these, triple negative breast carcinoma represents $10-17 \%$. Triple negative breast carcinomas, characterized by estrogen, progesterone and HER2 receptor negativity are very aggressive tumours with poor prognosis. Individualized treatment (tailored therapy) based on molecular biology markers of tumor and patient is the trend in clinical practice these days. However, molecular targets and predictors for the treatment of triple negative breast carcinoma do not currently exist.

Methods and results: This minireview focuses on biomarkers (HER1/EGFR, TOP2A and C-MYC genes) that may predict the response of triple negative breast carcinoma patients to chemotherapy and/or targeted biological treatment with a summary of current knowledge about them.

Conclusion: HER1 belonging to the HER family of receptors plays an important role in cell proliferation, migration and protection against apoptosis. HER1 protein could be targeted by monoclonal antibodies and/or tyrosine kinase inhibitors (TKIs). Given signal pathway complexity and HER family member cooperation, it may be better to simultaneously target a number of these receptors (e.g. HER1/HER2 by lapatinib). Thus, HER1 assessment could reveal a particular breast cancer patient group with probably good response to HER 1 targeted therapy. TOP2A gene, encoding topoisomerase II alpha (target for anthracyclines) is predictive of response to anthracycline therapy. TOP2A aberrations (amplification, deletion) are found in up to approximately 30-90\% of HER2 amplified breast cancer and amplifications are more common than deletions. Recent publications describe TOP2A amplification also in 2.7-8.8 \% HER2 nonamplified breast cancers. Patients with a pathologic complete response to anthracycline based neoadjuvant chemotherapy had a good overall prognosis regardless of molecular subtype of breast cancer. These results suggest that particularly tumors with a complete pathological response to anthracyclines could have TOP2A amplification. C-MYC encodes nuclear DNA binding proteins that regulate proliferation and apoptosis; amplification is associated with poor prognosis and hormonally negative breast carcinoma.

\section{INTRODUCTION}

About one million women worldwide are diagnosed with breast cancer (BC) every year. BC is the most common cancer in women. Data from the Czech National Oncology Registry (www.svod.cz) indicate the incidence has doubled since 1977 and in 2005 it reached $105.5 / 100000$ women with a mortality of 36.5/100 000 . Due to mamographic screening, stage I of the disease is diagnosed in nearly $35 \%$ of patients and stage II in more than $30 \%{ }^{1-2}$. Triple negative breast carcinoma (TNBC) represents $10-17 \%$ of all $\mathrm{BC}^{3}$. This minireview focuses on potential molecular targets and biomarkers that could be aimed or analyzed for prediction of response of TNBC patients to chemotherapy and/or biological targeted therapy.

\section{Pathology and Cytogenetics}

Ductal carcinoma is the most common histological category of malignant breast tumors, lobular carcinoma is the second major type while medullary carcinoma is relatively rare entity ${ }^{4}$. On diagnosis, the various presentations are classified on the basis of morphological and molecular examination. Prognosis is defined according to a number of parameters: tumor size and grade, the presence/absence of estrogen (ER) and/or progesterone (PR) receptors, HER2/neu (HER2, c-erbB2) protein, lymph node metastases and vascular or perineural tumor invasion. Other parameters, such as the proliferating index, ploidy, the presence of P53, cytokeratins (Ck), HER1 (EGFR), or TOP2A alterations, may also be useful for prognostic evaluation or as predicting therapeutic re- 
sponse. Classification according to immunohistochemistry (IHC) (based on expression profiles) distinguishes HER2+ (HER2+, ER+/-, Ck5/6 and EGFR +/-), luminal (HER $2-$, ER+, Ck5/6 and EGFR +/-) and basal-like (ER - , HER2 - , Ck5/6 and/or EGFR +) carcinomas ${ }^{5-7}$.

New insights into the molecular pathogenesis of $\mathrm{BC}$, with prognostic and predictive impact, have been gained using cytogenetics. $\mathrm{BC}$ tumor genomes have undergone major rearrangements. Hot spots for gains are routinely observed at 1q31-q32, 8q12 and 8q24 (MYC), 17q12 (HER2), 17q23-24 and 20q13, recurrent losses are present at $1 \mathrm{p}, 6 \mathrm{q}, 8 \mathrm{p}, 11 \mathrm{q} 23 \mathrm{qter}, 13 \mathrm{q}, 16 \mathrm{q}, 17 \mathrm{p}$ and 22q. The number of changes accumulates in advanced tumors ${ }^{8-9}$.

\section{Triple negative breast carcinomas}

Triple negative breast carcinomas (TNBC), characterized by absence of ER, PR and HER2 expression, are very aggressive tumors with poor prognosis. They more frequently affect younger patients ( $<50$ years), are more prevalent in African-American women, often present as interval cancers, initially are highly chemosensitive, but are significantly more aggressive than tumors pertaining to other molecular subgroups. This aggressiveness is best illustrated by the fact that the peak risk of recurrence is between the first and third years and the majority of deaths occur in the first 5 years following therapy. The majority of TNBC are high-grade invasive ductal carcinomas of no special type, metaplastic and medullary carcinomas $^{3,7}$.

\section{Individualized treatment (tailored therapy)}

Personal, custom made, therapy based on molecular biology markers of tumor and patient is the trend in clinical practice these days. The first clinically used predictive markers in $\mathrm{BC}$ were ER/PR tailoring response to antihormonal therapy ${ }^{10-11}$. The first cytogenetic predictor for BC treatment is the HER2 (HER2/neu, c-erbB2) gene amplification and protein overexpression. Monoclonal antibody trastuzumab (Herceptin) is used in the treatment of BC in patients who display HER2 positivity in invasive carcinoma component ${ }^{12-16}$. Nevertheless, predictors for the therapy of TNBC do not exist yet.

\section{HER1 gene and targeted therapy}

HER1 (also known as epidermal growth factor receptor, EGFR) belongs to the HER family of transmembrane receptors. HER 1 gene is located on $7 \mathrm{q} 12$. Its protein product - $170-\mathrm{kD}$ glycoprotein - plays an important role in cell proliferation, migration and protection against apoptosis mediated by subsequent activation of intracellular pathways. HER1 receptor can dimerize with all members of HER family and it has to create homo - or heterodimers to be functionally active ${ }^{17}$. Worse prognosis of breast tumors overexpressing HER 1 is connected with the above-mentioned effects on proliferation, migration and apoptosis. A study by Filardo et al. focuses on a receptor called G protein-coupled receptor 30 (GPR30), a member of the seven transmembrane receptor superfamily which is associated with specific estrogen binding and HER1 activation ${ }^{18}$. This crosstalk between receptors to- gether with the described influence on cell biology makes HER1 status assessment valuable even in the context of tumor hormonal dependence.

HER 1 protein could be targeted by monoclonal antibodies and/or synthetic tyrosine kinase inhibitors (TKIs). Monoclonal antibodies (cetuximab, panitumumab) are now clinically used in the treatment of colorectal cancer and head and neck carcinoma. TKIs are also important in the therapy of pancreatic and non-small cell lung cancer (NSCLC). HER1 targeted treatment with cetuximab in breast cancer have not produced satisfactory results probably because of the activation of downstream signal pathways ${ }^{7}$ or inadequate patient selection. TKIs are an option for targeted therapy in BC that is focused on HER 1 in particular. Agrawal et al. evaluated the results of studies testing TKIs (erlotinib, gefitinib) in BC and pointed out that HER1 protein must be present in targeted tumor tissue to obtain valuable treatment results. They also concluded that because of signal pathway complexity and HER family member cooperation it might be better to target more of these receptors at the same time ${ }^{19}$. Thus, HER1 assessment could reveal a particular BC patient group with probably good response to HER1 targeted therapy. Dual HER1/HER2 inhibitor lapatinib is now approved for BC patients with HER2 amplification/overexpression when trastuzumab therapy has failed. However, HER 1 gene status is not used in clinical practice to guide therapy in BC, although increased HER1 expression is detected in about $40 \%$ of BC. Particularly, HER 1 expression is higher (up to $80 \%$ ) in TNBC and metaplastic carcinoma (mostly basal-like), where it possibly substitutes ineffective, but otherwise major proliferation/survival pathways of $\mathrm{BC}$ induced by expression and activation of HER2, ER and PR proteins. HER 1 gene is amplified in nonselected series in 0-14\%, in metaplastic carcinoma up to $28 \%{ }^{20-26}$. Interestingly, HER1 and C-MYC coamplification can be also present ${ }^{24}$. More insights into significance of HER1/ HER2 status in outcome of patients treated with TKIs should provide undergoing phase II clinical trial which examines the effect of lapatinib monotherapy in metastatic breast cancer patients with HER2 positive vs. HER1 positive circulating cells in peripheral blood ${ }^{27}$.

\section{TOP2A}

The TOP2A gene, located on 17q21-22, encoding topoisomerase II alpha (molecular target for anthracyclines) is predictive of response to anthracycline therapy. TOP2A aberrations (amplification, deletion) are found in up to approximately $30-90 \%$ of HER 2 amplified BC and amplifications are more common than deletions. Good response to anthracyclines is associated with TOP2A amplification while deletion may be accompanied by resistance. On the other hand, clinical study results are not uniform. Knoop et al. reported in a nonselected series, an association between TOP2A amplification and good response to anthracycline based regimens. Surprisingly, better response to anthracyclines than CMF [cyclophosphamid, methotrexat, 5-fluorouracil (5-FU)] was found in subgroup of patients with TOP2A deletion compared to normal TOP2A status ${ }^{12,2836}$, probably demonstrating high- 
er overall efficacy of antracycline based therapies. One recent study showed that TOP2A deletion was associated with poor prognosis in HER2 amplified BC. Clarification of the mechanism of this association will require additional studies ${ }^{37}$. Burgess et al. identified in a nonselected series, TOP2A expression levels as major determinants of response to the topoisomerase II inhibitor doxorubicin and showed that suppression of TOP2A levels produces resistance to doxorubicin in vitro and in vivo ${ }^{38}$. However in the case of TOP2A there is no correlation between amplification and overexpression ${ }^{28,39}$. Moreover, our study in locally advanced BC showed HER2 and TOP2A gene status changes after antracycline based chemotherapy ${ }^{40}$, and thus number of published data can be biased by treatments preceding tumor biopsy.

Recent publications describe TOP2A amplification in 2.7-8.8\% of HER2 non-amplified $\mathrm{BC}^{35,41-43}$. Tan et al. found TNBC associated with TOP2A protein expression and poor response to adjuvant anthracyclines; in this study including 31 cases of TNBC TOP2A amplification was not detected using chromogenic in situ hybridization $^{25}$. However, as pointed out above, in contrast to HER-2 status, there is no correlation between TOP2A gene amplification and overexpression ${ }^{28,39}$. Patients with basal-like BC (overlapped with TNBC) ${ }^{3}$ treated with neoadjuvant anthracyclines also have poor prognosis (distant disease free survival, DDFS and overall survival, OS $)^{44}$. It may be hypothesized that the lack of HER2 and TOP2A co-amplification could be the cause. However, patients with a pathologic complete response to anthracycline based neoadjuvant chemotherapy had a good prognosis regardless of subtype (basal-like, luminal-like, HER2+/ ER-) (TN paradox $)^{44}$. These results suggest that at least individuals with a complete pathological response to anthracyclines could have TOP2A amplification or overexpression. Unfortunately, in the above discussed study by Carey et al. TOP2A status was not assessed. Weigelt et al. studied metaplastic BC (a subgroup of TNBC) by microarray expression analysis and found significant downregulation in PTEN and TOP2A which might partly explain observed differences in response to chemotherapy in $\mathrm{TNBC}^{45}$.

\section{C-MYC}

The $8 \mathrm{q}$ chromosome arm that harbors the C-MYC gene is frequently altered in BC. C-MYC encodes nuclear DNA binding proteins that regulate proliferation and apoptosis. The MYC protein is directly involved in regulating more than 1500 genes $^{46-52}$. C-MYC amplification is one of the most frequent aberrations in $\mathrm{BC}$ that has been detected in 1-94\% of patients in different studies. Amplification is clearly associated with poor prognosis: patients suffer from early relapses and have poor OS. C-MYC amplification is associated with ER - and PR - breast carcinoma. C-MYC deregulation occurs preferentially in young patients ${ }^{53}$. C-MYC protein may affect the response to chemotherapy probably through DNA damage response regulation ${ }^{46,54-60}$. Interestingly, C-MYC amplification in colon carcinoma predicts better response to 5-FU adjuvant chemotherapy [disease free survival
(DFS) and OS have been improved by $30 \%$ ], but only in p5 3 wild tumors ${ }^{61-62}$. This type of study in $\mathrm{BC}$ has not been published. Nonetheless, Rakha et al. described improvement of the poor prognosis of TNBC by treatment with the CMF regimen ${ }^{63}$. TNBC often have amplified HER1 gene $^{21}$ and according to the described C-MYC coamplification in $\mathrm{BC}^{24}$, so we may hypothesize the possibility that the tumors responding favorably to the 5-FU containing regiment $\mathrm{CMF}$ were those with $\mathrm{C}-\mathrm{MYC}$ amplification. Suppression of C-MYC transcription in BC cells after 5-FU treatment supports the direct effect of 5-FU on the oncogene activity, probably mediated by upstream signaling inhibition ${ }^{64}$.

\section{Adjuvant/neoadjuvant chemotherapy}

Adjuvant chemotherapy is recommended according to the international guidelines for patients in clinical stage IB to IIIB of breast carcinoma, when the tumor is larger than $1 \mathrm{~cm}$ and/or lymphonodes are positive, respectively. However in TNBC even smaller tumors are recommended to consider adjuvant chemotherapy with respect to diseases recurrence risk and high aggressivity of this tumor type. For treating TNBC, anthracycline regimens are mostly used ${ }^{65}$. However, there are no data on the real patient benefits. It is assumed that chemotherapy is more successful in ER - than ER+ patients and appears to be more appropriate for young premenopausal women ${ }^{10-11,66}$. Since the chemotherapy has serious side-effects, finding an accurate predictor of response could determinate patients who would profit from adjuvant chemotherapy. However, current knowledge indicates the possibility of CMF renascence in treatment of TNBC associated with poor prognosis and limited therapeutic options, particularly in adjuvant settings. It is hoped that poor prognosis of TNBC could be improved using CMF treatment ${ }^{25,63}$.

Neoadjuvant chemotherapy is a newer possibility recommended for patients with expected good response to chemotherapy administration (ER-, PR-, non-lobular, fast proliferating, luminal B and high grade tumors), mainly in patients with locally advanced disease potentially indicated for breast saving surgery. Currently applied regimens are mostly based on a combination of anthracyclines and taxanes which suggests again the importance of further comparative studies evaluating the efficacy of CMF, anthracycline based or other therapies in $\mathrm{TNBC}^{65}$.

\section{CONCLUSION}

Triple negative breast carcinoma (TNBC) represents $10-17 \%$ of all $\mathrm{BC}^{3}$ with poor prognosis. Specific predictors for its targeted treatment are still lacking. However, TOP2A status could predict sensitivity to anhracycline therapy in a small proportion of TNBC patients. Chemotherapy optimization (CMF vs. other regimens) needs to be evaluated in large clinical studies. The complexity of intracellular signal transducing pathways also demands further investigations. This raises the importance of dual inhibitors like lapatinib or molecules preventing dimerisation of receptors like pertuzumab at the 
level of HER2 and other members of the HER family ${ }^{19}$. Together with the treatment approaches described there is also the possibility of combination with drugs acting at lower levels of signal transmission.

\section{ACKNOWLEDGEMENTS}

We would like to acknowledge support of grants from the Czech Ministry of School and Education (MSM6198959216 and LC07017) and EEA/Norway Financial Mechanisms (CZ0099).

\section{REFERENCES}

1. www.svod.cz.

2. www.uzis.cz

3. Reis-Filho JS, Tutt AN. Triple negative tumours: a critical review. Histopathology 2008;52:108-18.

4. Tavassoli FA, Devilee P. World health organization classification of tumors. Pathology and genetics of tumours of the breast and female genital organs. IARC Press: Lyon; 2003.

5. Sorlie T, Tibshirani R, Parker J, Hastie T, Marron JS, Nobel A et al. Repeated observation of breast tumor subtypes in independent gene expression data sets. PNAS 2003;100:8418-23.

6. Nielsen TO, Hsu FD, Jensen K, Cheang M, Karaca G, Hu Z et al. Immunohistochemical and clinical characterization of the basal-like subtype of invasive breast carcinoma. Clin Cancer Res 2004; 10:5367-5374.

7. Shiu KK, Tan DS, Reis-Filho JS. Development of therapeutic approaches to 'triple negative' phenotype breast cancer. Expert Opin Ther Targets 2008;12:1123-37.

8. Tumors of the Breast. In: Heim S, Mitelman F, editors. Cancer Cytogenetics. New York: Wiley-Liss; 1995, p. 369-388.

9. Struski S, Doco-Fenzy M, Cornillet-Lefebvre P. Compilation of published comparative genomic hybridization studies. Cancer Genet Cytogenet 2002;135,63-90.

10. Pritchard KI. Adjuvant therapy of the very young woman. Breast 2007;16 Suppl 2:136-46.

11. Pritchard KI. Adjuvant therapy for breast cancer: we are solving the puzzle, but pieces are still missing. JNCI 2007;99:494-5.

12. Järvinen TA, Tanner M, Rantanen V, Bärlund M, Borg A, Grénman $S$ et al. Amplification and deletion of topoisomerase IIalpha associate with ErbB-2 amplification and affect sensitivity to topoisomerase II inhibitor doxorubicin in breast cancer. Am J Pathol 2000;156:839-847.

13. Slamon DJ, Leyland-Jones B, Shak S, Fuchs H, Paton V, Bajamonde A et al. Use of chemotherapy plus a monoclonal antibody against HER2 for metastatic breast cancer that overexpresses HER2. NEJM 2001;344(11):783-792.

14. Wang S, Saboorian MH, Frenkel E, Hynan L, Gokaslan ST, Ashfaq R. Laboratory assessment of the status of Her-2/neu protein and oncogene in breast cancer specimens: comparison of immunohistochemistry assay with fluorescence in situ hybridisation assays. J Clin Pathol 2000;53:374-81.

15. Perez EA, Roche PC, Jenkins RB, Reynolds CA, Halling KC, Ingle JN et al. HER2 testing in patients with breast cancer: poor correlation between weak positivity by immunohistochemistry and gene amplification by fluorescence in situ hybridization. Mayo Clin Proc 2002;77:148-54.

16. Roche PC, Suman VJ, Jenkins RB, Davidson NE, Martino S, Kaufman PA et al. Concordance between local and central laboratory HER2 testing in the breast intergroup trial N9831. JNCI 2002;94:855-7.

17. Hynes NE, Lane HA. ERBB receptors and cancer: the complexity of targeted inhibitors. Nat Rev Cancer. 2005;5:341-54.

18. Filardo EJ, Quinn JA, Sabo E. Association of the membrane estrogen receptor, GPR30, with breast tumor metastasis and transactivation of the epidermal growth factor receptor. Steroids. 2008; 73:870-5

19. Agrawal A, Gutteridge E, Gee JM, Nicholson RI, Robertson JF Overview of tyrosine kinase inhibitors in clinical breast cancer. Endocr Relat Cancer. 2005;12:S135-44.

20. Hobday TJ, Perez EA. Molecularly targeted therapies for breast cancer. Cancer Control 2005;12.73-81.

21. Reis-Filho JS, Milanezi F, Carvalho S, Simpson PT, Steele D, Savage K et al. Metaplastic breast carcinomas exhibit EGFR, but not HER2, gene amplification and overexpression: immunohistochemical and chromogenic in situ hybridization analysis. Breast Cancer Res 2005;7:R1028-35.

22. Siziopikou KP, Ariga R, Proussaloglou KE, Gattuso P, Cobleigh $M$. The challenging estrogen receptor-negative/ progesterone receptor-negative/HER-2-negative patient: a promising candidate for epidermal growth factor receptor-targeted therapy? Breast $\mathrm{J}$ 2006;12,360-2.

23. Siziopikou KP, Cobleigh M. The basal subtype of breast carcinomas may represent the group of breast tumors that could benefit from EGFR-targeted therapies. Breast 2007;16,104-7.

24. Al-Kuraya K, Schraml P, Torhorst J, Tapia C, Zaharieva B, Novotny $\mathrm{H}$ et al. Prognostic relevance of gene amplifications and coamplifications in breast cancer. Cancer Res 2004;64,8534-40.

25. Tan DS, Marchió C, Jones RL, Savage K, Smith IE, Dowsett M et al. Triple negative breast cancer: molecular profiling and prognostic impact in adjuvant anthracycline-treated patients. Breast Cancer Res Treat 2008;111:27-44.

26. Reis-Filho JS, Pinheiro C, Lambros MB, Milanezi F, Carvalho S, Savage K et al. EGFR amplification and lack of activating mutations in metaplastic breast carcinomas. J Pathol 2006;209:445-53.

27. www.clinicaltrials.gov.

28. Bouchalová K, Trojanec R, Kolár Z, Cwiertka K, Cernáková I, Mihál V et al. Analysis of ERBB2 and TOP2A gene status using fluorescence in situ hybridization versus immunohistochemistry in localized breast cancer. Neoplasma 2006;53,393-401.

29. Järvinen TA, Liu ET. Simultaneous amplification of HER-2 (ERBB2) and topoisomerase IIalpha (TOP2A) genes-molecular basis for combination chemotherapy in cancer. Curr Cancer Drug Targets 2006;6:579-602.

30. Keith WN, Douglas F, Wishart GC, McCallum HM, George WD, Kaye SB et al. Co-amplification of erbB2, topoisomerase II alpha and retinoic acid receptor alpha genes in breast cancer and allelic loss at topoisomerase I on chromosome 20. Eur J Cancer 1993;29A,1469-75.

31. Smith K, Houlbrook S, Greenall M, Carmichael J, Harris AL. Topoisomerase II alpha co-amplification with erbB2 in human primary breast cancer and breast cancer cell lines: relationship to m-AMSA and mitoxantrone sensitivity. Oncogene 1993;8,933-8.

32. Watt PM, Hickson ID. Structure and function of type II DNA topoisomerases. Biochem J 1994;303,681-95.

33. Wosikowski K, Schuurhuis D, Kops GJ, Saceda M, Bates SE. Altered gene expression in drug-resistant human breast cancer cells. Clin Cancer Res 1997;3,2405-14.

34. Harris LN, Yang L, Tang C, Yang D, Lupu R. Induction of sensitivity to doxorubicin and etoposide by transfection of MCF-7 breast cancer cells with heregulin beta-2. Clin Cancer Res 1998;4,1005-12.

35. Knoop AS, Knudsen H, Balslev E, Rasmussen BB, Overgaard J, Nielsen KV et al. Retrospective analysis of topoisomerase IIa amplifications and deletions as predictive markers in primary breast cancer patients randomly assigned to cyclophosphamide, methotrexate, and fluorouracil or cyclophosphamide, epirubicin, and fluorouracil: Danish Breast Cancer Cooperative Group. J Clin Oncol 2005;23: 7483-90.

36. Arriola E, Rodriguez-Pinilla SM, Lambros MB, Jones RL, James M, Savage K et al. Topoisomerase II alpha amplification may predict benefit from adjuvant anthracyclines in HER2 positive early breast cancer. Breast Cancer Res Treat 2007;106:181-9.

37. Usha L, Tabesh B, Morrison LE, Rao RD, Jacobson K, Zhu A et al. Topoisomerase II alpha gene copy loss has adverse prognostic significance in ERBB2-amplified breast cancer: a retrospective study of paraffin-embedded tumor specimens and medical charts. J Hematol Oncol 2008;1:12Epub ahead of print. 
38. Burgess DJ, Doles J, Zender L, Xue W, Ma B, McCombie WR et al. Topoisomerase levels determine chemotherapy response in vitro and in vivo. Proc Natl Acad Sci U S A 2008;105:9053-8.

39. Mueller RE, Parkes RK, Andrulis I, O'Malley FP. Amplification of the TOP2A gene does not predict high levels of topoisomerase II alpha protein in human breast tumor samples. Genes Chromos Cancer 2004;39,288-97.

40. Hajduch M, Palacova M, Trojanec R, Dusek L, Petrakova K, Spackova K et al. Anthracycline based chemotherapy decreases amplification status of Her-2/neu and topoisomerase II alpha genes in locally advanced breast cancer. ASCO, 40th Annual Meeting, June 5-8, 2004, New Orleans, LA. Abstract 9521 in J Clin Oncol, 2004 ASCO Annual Meeting Proceedings (Post-Meeting Edition) 2004; 22(14S)

41. Bofin AM, Ytterhus B, Hagmar BM. TOP2A and HER-2 gene amplification in fine needle aspirates from breast carcinomas. Cytopathology 2003; 14:314-9.

42. Hagen AI, Bofin AM, Ytterhus B, Maehle LO, Kjellevold KH, Myhre $\mathrm{HO}$ et al. Amplification of TOP2A and HER-2 genes in breast cancers occurring in patients harbouring BRCA1 germline mutations. Acta Oncol 2007;46:199-203.

43. Nielsen KV, Ejlertsen B, Møller S, Jørgensen JT, Knoop A, Knudsen $\mathrm{H}$ et al. The value of TOP2A gene copy number variation as a biomarker in breast cancer: Update of DBCG trial 89D. Acta Oncol 2008;47:725-34.

44. Carey LA, Dees EC, Sawyer L, Gatti L, Moore DT, Collichio F et al. The triple negative paradox: primary tumor chemosensitivity of breast cancer subtypes. Clin Cancer Res 2007;13,2329-34.

45. Weigelt B, Kreike B, Reis-Filho JS. Metaplastic breast carcinomas are basal-like breast cancers: a genomic profiling analysis. Breast Cancer Res Treat. 2008Epub ahead of print.

46. Nass SJ, Dickson RB. Defining a role for c-Myc in breast tumorigenesis. Breast Cancer Res Treat 1997;44:1-22.

47. Dang CV, Resar LM, Emison E, Kim S, Li Q, Prescott JE et al Function of the c-Myc oncogenic transcription factor. Experimental Cell Research 1999;253:63-77.

48. Lee CM, Reddy EP. The v-myc oncogene. Oncogene 1999;18:29973003.

49. Prendergast GC. Mechanisms of apoptosis by c-Myc. Oncogene 1999; 18:2967-87.

50. Schmidt EV. The role of c-myc in cellular growth control. Oncogene 1999; 18:2988-96.

51. Bidwell GL 3rd, Raucher D. Enhancing the antiproliferative effect of topoisomerase II inhibitors using a polypeptide inhibitor of c-Myc. Biochem Pharmacol 2006;71:248-56.

52. Cohen DE, Prochownik EV. A functional hierarchy for c-Myc target genes? Lessons from MT-MC1. Cell Cycle 2006;5:392-3.
53. Anders CK, Acharya CR, Hsu DS, Broadwater G, Garman K, Foekens JA et al. Age-specific differences in oncogenic pathway deregulation seen in human breast tumors. PloS ONE 2008;3,e1373.

54. Berns EM, Klijn JG, van Putten WL, van Staveren IL, Portengen H, Foekens JA. c-myc amplification is a better prognostic factor than HER2/neu amplification in primary breast cancer. Cancer Res 1992;52:1107-13.

55. Klijn JG, Berns EM, Foekens JA. Prognostic factors and response to therapy in breast cancer. Cancer Surv 1993;18:165-97.

56. Afify A, Bland KI, Mark HF. Fluorescent in situ hybridization assessment of chromosome 8 copy number in breast cancer. Breast Canc Res Treat 1996;32(2):201-8.

57. Gewirtz DA, Randolph JK, Chawla J, Orr MS, Fornari FA Induction of DNA damage, inhibition of DNA synthesis and suppression of c-myc expression by the anthracycline analog, idarubicin (4-demethoxy-daunorubicin) in the MCF-7 breast tumor cell line. Cancer Chemother Pharmacol 1998;41:361-69.

58. Mark HF, Taylor W, Brown S, Samy M, Sun CL, Santoro K et al. Abnormal chromosome 8 copy number in stage I to stage IV breast cancer studied by fluorescence in situ hybridization. Cancer Genet Cytogenet 1999;108:1-5.

59. Aulmann S, Adler N, Rom J, Helmchen B, Schirmacher P, Sinn HP. et al: c-myc amplifications in primary breast carcinomas and their local recurrences. J Clin Pathol 2006;59:424-8.

60. Corzo C, Corominas JM, Tusquets I, Salido M, Bellet M, Fabregat $\mathrm{X}$ et al. The MYC oncogene in breast cancer progression: from benign epithelium to invasive carcinoma. Cancer Genet Cytogenet 2006;165:151-6.

61. Arango D, Corner GA, Wadler S, Catalano PJ, Augenlicht LH. c-myc/p53 interaction determines sensitivity of human colon carcinoma cells to 5-fluorouracil in vitro and in vivo. Cancer Res 2001;61:4910-15.

62. Barratt PL, Seymour MT, Stenning SP, Georgiades I, Walker C, Birbeck K et al. DNA markers predicting benefit from adjuvant fluorouracil in patients with colon cancer: a molecular study. Lancet 2002;360:1381-91.

63. Rakha EA, El-Sayed ME, Green AR, Lee AH, Robertson JF, Ellis IO. Prognostic markers in triple-negative breast cancer. Cancer 2007; 109,25-32.

64. Hernández-Vargas H, Ballestar E, Carmona-Saez P, von Kobbe C, Bañón-Rodríguez I, Esteller M et al. Transcriptional profiling of MCF7 breast cancer cells in response to 5-Fluorouracil: relationship with cell cycle changes and apoptosis, and identification of novel targets of p53. Int J Cancer 2006; 119:1164-75.

65. www.linkos.cz.

66. Adjuvant Breast Cancer Trials Collaborative Group. Polychemotherapy for early breast cancer: results from the international adjuvant breast cancer chemotherapy randomized trial. JNCI 2007;99:506-15. 
